\title{
Reproductive Life History as Gastric Cancer Risk for Females : Case-Control Study
}

\author{
Itsuro Ogimoto1,3, Takesumi Yoshimura1, and Masato Ikeda1,2
}

\begin{abstract}
The purpose of this study was to investigate whether the reproductive life history, including hormonal environment, was a risk factor for gastric cancer in females by age groups or by histological subgroups. A case-control study with incident cases accompanied by individually matched one or two controls was carried out, using self administered questionnaire which included personal profile, smoking and drinking habits, dietary habits, past history of disease and reproductive life history. Analysis was made for 116 females cases and matched 144 controls separately by two histological type subgroups (differentiated and undifferentiated type) and by two age groups (young and older), using proportional hazard model to obtain relative risks with $95 \%$ C.l. For the undifferentiated gastric cancer in female under 40 years of age, mean of cumulative estradiol concentration (CEC) during all pregnant period and mean pregnant period per pregnancy revealed increased relative risk (R.R.) of 7.7 (95\% C.I. : 1.41-41.75) (for each $1 \mathrm{ng} / \mathrm{ml}$ ) and 3.1 (95\% C.I. : 1.01-9.55) (for each 10 weeks), respectively. In the same group, 4 bowls or more rice consumption per day and drinking showed significant protective effect (R.R. : 0.20, 95\% C.I. : $0.04-0.90$ and R.R. : 0.23 , 95\% C.I.: $0.07-0.70$, respectively). For differentiated gastric cancer in both age groups and undifferentiated one in older female, these factors stated above have no striking effect for gastric cancer occurrence. For differentiated type, several dietary habits were suggested to be risk factors for gastric cancer, although they were not statistically significant. On the other hand, for undifferentiated type, this tendency was not observed. This study suggests that etiologic factors for gastric cancer might be differed between histological types, and that undifferentiated type gastric cancer in young female with pregnancy has some etiological relation with reproductive histories.
\end{abstract}

$J$ Epidemiol, $1995 ; 5: 177-185$.

stomach cancer, reproductive life history, histological type, age

Griffis pointed out that the sex ratio of age specific gastric cancer mortalities among younger people is smaller than that among older people in all countries wherever gastric cancer mortalities are either high or low. That is, the mean of sex ratios in the younger group (younger than 40 ) is under 1.5, but that in the older group (between 50 and 59) is over $2.0^{11}$. Reproductive activities of young females, especially pregnancy, have been considered to be related to this phenomenon ${ }^{1,2)}$. One of the authors (T.Y.) suggested that lower age at the first pregnancy or at the first birth and higher age at the menarche were the risk factors of gastric cancer in young female ${ }^{3)}$.
Furukawa and his colleagues suggested that estradiol and pregnancy might increase risk of undifferentiated type gastric cancer in young females based on their experiments of rat ${ }^{4,5)}$. But, no report had considered the length of pregnancy and the dose of estrogens in the relation with the gastric cancer risk in human being, though estrogens were considered to be related factors for gastric cancer ${ }^{2,4-7)}$. In the present study, it was intended to clarify whether the reproductive life history is a gastric cancer risk for females, using semi-quantitative variables for estrogens based on detailed information of reproductive histories.

Received June 6, 1995; accepted November 11, 1995.

${ }^{1}$ Department of Clinical Epidemiology, Institute of Industrial Ecological Sciences, University of Occupational and Environmental Health, Japan.

'Department of Occupational Health Economics, Institute of Industrial Ecological Sciences, University of Occupational and Environmental Health, Japan.

${ }^{3}$ Presently; Department of Public Health, School of Medicine, Kurume University, Japan.

Address for correspondence: Itsuro Ogimoto, Department of Public Health, School of Medicine, Kurume University, 67 Asahimachi Kurume, 830 Japan. 


\section{MATERIALS AND METHODS}

\section{Study subjects}

Cases were histologically confirmed female gastric cancer incident patients aged less than 40 (young), and aged fifties (50-59) (older), admitted at 12 departments of surgery and 1 department of endoscopy in 11 large hospitals in Fukuoka prefecture, Japan, from the first day of 1986 through the last day of 1988. Ages of cases were defined based on the day of the first visit. Histological types of cases were classified into two categories, differentiated and undifferentiated, according to Hanai's criteria ${ }^{8)}$ based on the histological diagnosis determined at the pathological department in each hospital using resected or biopsied specimens.

In the young group, two controls for each index case were chosen in order to increase the power of the study because the number of young cases was expected to be small. Controls were chosen from inpatients of the same hospital matched by date of birth (within two years), sex, ward of the hospital and the date of admission to the hospital (within two months). Patients with malignant neoplasms and endocrine diseases were excluded from the controls. When more than two patients were satisfied with the selection criteria of controls, two with the nearest birth date to the index case were selected as controls.

In the older group, one control was selected for each case, using the same selection criteria as in the young group.

The cases and controls chosen were requested to complete the self-administered questionnaires, while in the wards or after discharge. Controls were chosen and surveyed soon after or at the same time as the cases were surveyed.

The questionnaire consists of personal profile, smoking and drinking habits, dietary habits, past history of disease, and detailed reproductive life history.

\section{Analysis}

To estimate exposure to estradiol, the variable named 'cumulative estradiol concentration (CEC)' was introduced by calculating the area under the estradiol concentration curve in each reproductive stage, that is the usual menstrual cycle and the pregnant stage, using Hertogh's data ${ }^{9)}$. CEC is expressed as follows.

CEC (cumulative estradiol concentration) $\mathrm{ng} \cdot \mathrm{w} / \mathrm{ml}$

$$
=\int \begin{aligned}
& \text { age at the frst visit to the out patient clinic } \\
& \text { age at the menarche }
\end{aligned}
$$

Where $f(x)$ expresses time depending estradiol concentration. Time $(x)$ is measured by week of menstrual cycle or of pregnancy course. Unit of the CEC is expressed with 'concentration $(\mathrm{ng} / \mathrm{ml})$ multiplied by week (w)' as 'ng $\cdot \mathrm{w} / \mathrm{ml}$ '.

$$
f(x)=\left\{\begin{array}{c}
0.06 x-0.02 \text { (for } 0-8 \text { week in each pregnancy) } \\
0.48 x-3.59 \text { (for } 9-22 \text { week in each preg- } \\
\text { nancy) } \\
0.52 x-2.34 \text { (for over } 22 \text { week in each preg- } \\
\text { nancy) } \\
0.11 x \text { (for ordinal menstrual cycle, total) }
\end{array}\right.
$$

Direct estimate of estradiol exposure for the subject should be expressed by CEC, blood volume and turn over cycle. In the present study, however, blood volume and turn over were assumed to be constant among females studied. Therefore, CEC was adopted as a surrogate of direct estimate of estradiol exposure. Estradiol concentration were cumulated only during pregnancy for 'total CEC during all pregnant period', and total CEC during all pregnant period was divided by total weeks of pregnancy ('Total pregnant period') for 'mean CEC during all pregnant period'.

Total pregnant period, mean pregnant period per pregnancy, total CEC during all pregnancy and mean CEC during all pregnant period were calculated for only female with pregnancy.

For the analysis of dietary, drinking and smoking habits,

\begin{tabular}{|c|c|c|}
\hline Diagnosis & No. of Cases & $\%$ \\
\hline Differentiated type & 40 & \\
\hline Papillaly adenocarcinoma & 1 & 0.9 \\
\hline Well differentiated tubular adenocarcinoma & 9 & 7.8 \\
\hline Moderately differentiated tubular adenocarcinoma & 13 & 11.2 \\
\hline Moderately differentiated adenocarcinoma & 8 & 6.9 \\
\hline Tubular adenocarcinoma & 1 & 0.9 \\
\hline Mucinous adenocarcinoma & 2 & 1.7 \\
\hline Differentiated adenocarcinoma & 6 & 5.2 \\
\hline Undifferentiated type & 76 & \\
\hline Poorly differentiated carcinoma & 62 & 53.4 \\
\hline Signet-ring cell carcinoma & 14 & 12.1 \\
\hline Total & 116 & 100.0 \\
\hline
\end{tabular}

Table 1. Histological diagnosis of differentiated and undifferentiated gastric cancer cases. 
Table 2. Number of cases and referents according to case's histological types.

\begin{tabular}{|c|c|c|c|c|c|c|}
\hline \multirow{2}{*}{ Histological types } & \multicolumn{2}{|c|}{ Young } & \multicolumn{2}{|c|}{ Old } & \multicolumn{2}{|c|}{ Total } \\
\hline & case & control & case & control & case & control \\
\hline Differentiated & 9 & 16 & 31 & 31 & 40 & 47 \\
\hline Undifferentiated & 29 & 50 & 47 & 47 & 76 & 97 \\
\hline Total & 38 & 66 & 78 & 78 & 116 & 144 \\
\hline
\end{tabular}

the relative risks were calculated according to dichotomous variables. For the factors concerning to the reproductive life history, means were calculated by age and histological type for cases and controls respectively. Then, paired t-test was done to see the differences between cases and controls.

Relative risks were calculated using the conditional logistic regression method with PHREG on SAS, based on the proportional hazard model by $\mathrm{Cox}^{10)}$.

Analysis was done separately in four subgroups based on age, and two histological types.

\section{RESULTS}

Among the female patients admitted to the hospitals during the study period, 202 patients (young: 65, older : 137) with gastric cancer satisfied the criteria for caseness. Of these patients, 33 cases were excluded because of poor health condition or death. Then, 169 cases (young : 55, older : 114) were requested to complete the questionnaire. Among them, 127 cases (young: 41, older: 86) returned questionnaire (Return rate: 75.1\%). Among these 127 cases, 116 subjects, who had filled out the questionnaire satisfactorily and had suitable controls who satisfied the matching criteria mentioned above, were used for analysis. Of these 116 cases, 38 were young and 78 were older. Number of case series by histological type are shown in Table 1.

Number of controls who had been selected and surveyed were 259. Among them, 187 possible controls returned the questionnaire (Return rate : $72.2 \%$ ). Of these 187, 144 controls both with questionnaire satisfied and with their index cases were analyzed. The number of cases and controls analyzed are shown in Table 2 by histological type of cases. Disease distribution for controls are shown in Table 3.

\section{Daily life habits and past history}

Relative risks for daily life habits and past history, and their $95 \%$ confidence intervals for each item are shown for the young in Table 4 and for the older in Table 5 by histological type.

In the undifferentiated type of the young group, relative risk for drinking habit (drinker vs. non-drinker) and for rice intake ( 4 bowls or more a day vs. less than that) were 0.23 (95\% C.I. : 0.07-0.70) and 0.20 (95\% C.I. : 0.04-0.90), respectively as shown in Table 4 . No noticeable relative risks for known risk or preventive factors were shown in this group. In the differentiated type of the young group, relative risks for drinking habit, pickled vegetables, meat products and dairy products seemed to be increased although these were not statistically significant. In this subgroup, relative risks for salty foods and smoked foods were not estimated, but in these case-control sets all cases had consumed these food more than once a day, on the other hand, all controls had not.

In the undifferentiated type in older age groups, the relative risks for pickled vegetables, salty foods, and dried

Table 3. Clinical diagnosis of referents.

\begin{tabular}{llrr}
\multicolumn{1}{c}{ Diagnosis according to ICD9 } & $\mathrm{N}$ & $\%$ \\
\hline Infectious diseases & $(001-139)$ & 8 & 5.6 \\
Neoplasms (benign only) & $(210-229)$ & 2 & 1.4 \\
Metabolic diseases & $(270-279)$ & 2 & 1.4 \\
Diseases of the blood and blood-forming organs & $(280-289)$ & 3 & 2.1 \\
Diseases of the circulatory system & $(390-459)$ & 8 & 5.6 \\
Diseases of the respiratory system & $(460-519)$ & 4 & 2.8 \\
Diseases of the gastro-intestinal system & $(520-569,578)$ & 34 & 23.6 \\
Cholelithiasis & $(574)$ & 61 & 42.4 \\
Diseases of the other digestive system & $(570-573,575-577)$ & 15 & 10.4 \\
Diseases of the genitourinal system & $(580-629)$ & 2 & 1.4 \\
Diseases of the skin and subcutaneous tissue & $(680-709)$ & 1 & 0.7 \\
Diseases of the musculoskeletal system & $(710-739)$ & 1 & 0.7 \\
Check-up & - & 3 & 2.1 \\
\hline Total & & 144 & 100.0 \\
\hline
\end{tabular}


Table 4. Relative risks for gastric cancer by histological subgroups among young females.

\begin{tabular}{|c|c|c|c|c|c|c|c|}
\hline \multirow[b]{2}{*}{ Factor } & \multirow[b]{2}{*}{ Definition } & \multicolumn{3}{|c|}{ Differentiated carcinoma } & \multicolumn{3}{|c|}{ Undifferentiated carcinoma } \\
\hline & & $\begin{array}{l}\text { No. of } \\
\text { Cases }\end{array}$ & $\begin{array}{c}\text { Relative } \\
\text { risk* }\end{array}$ & 95\% C.I. & $\begin{array}{l}\text { No. of } \\
\text { Cases }\end{array}$ & $\begin{array}{l}\text { Relative } \\
\text { risk }\end{array}$ & 95\% C.I. \\
\hline Smoking & Smoker or Ex-smoker/Non-smoker & 9 & - & - & 28 & 0.73 & $0.28-1.92$ \\
\hline Drinking & Drinker or Ex-drinker/Non-drinker & 9 & 6.36 & $0.71-56.94$ & 29 & 0.23 & $0.07-0.70$ \\
\hline Rice & 4 bowls or more per day/Less than 4 & 8 & 0.47 & $0.04-5.68$ & 28 & 0.20 & $0.04-0.90$ \\
\hline Noodles & Several a week or more/Less than that & 8 & 1.00 & $0.09-11.03$ & 29 & 1.40 & $0.46-4.30$ \\
\hline $\begin{array}{l}\text { Consumption of the soup } \\
\text { of the noodles }\end{array}$ & Almost all/Lexs than that & 8 & 1.00 & $0.05-18.92$ & 29 & 0.46 & $0.10-2.19$ \\
\hline Bread & 5 times per week or more / Less than 5 & 5 & 0.62 & $0.06-7.00$ & 18 & 0.67 & $0.19-2.38$ \\
\hline Pickled vegetables & Once a day or more/Less than once & 8 & 4.00 & $0.36-44.12$ & 29 & 0.78 & $0.32-1.93$ \\
\hline Salty foods & Once a day or more/Less than once & 8 & - & - & 28 & 1.43 & $0.27-7.48$ \\
\hline Miso soup & Once a day or more/Less than once & 8 & 0.47 & $0.04-5.68$ & 28 & 0.89 & $0.35-2.29$ \\
\hline Dried fish, smoked foods & Once a day or more/Less than once & 8 & - & - & 29 & 0.48 & $0.16-1.45$ \\
\hline Broiled fish & Once a day or more/Less than once & 8 & 1.41 & $0.09-23.57$ & 29 & 0.85 & $0.32-2.26$ \\
\hline Meat products & Once a day or more/Less than once & 8 & 4.00 & $0.41-39.00$ & 29 & 1.43 & $0.55-3.72$ \\
\hline Vegetables & Once a day or more/Less than once & 8 & 2.11 & $0.36-12.21$ & 29 & 0.74 & $0.27-2.02$ \\
\hline Edible wild plant & Once a day or more/Less than once & 8 & - & - & 29 & 2.00 & $0.13-31.98$ \\
\hline Fruits & Once a day or more/Less than once & 8 & 0.22 & $0.02-2.12$ & 29 & 1.15 & $0.47-2.80$ \\
\hline Milk & Once a day or more/Less than once & 8 & 2.06 & $0.33-13.05$ & 28 & 0.88 & $0.32-2.40$ \\
\hline Dairy products & Once a day or more/Less than once & 8 & 3.77 & $0.4-35.47$ & 29 & 1.11 & $0.37-3.34$ \\
\hline Coffee & Once a day or more/Less than once & 8 & - & - & 23 & 2.11 & $0.18-25.27$ \\
\hline History of gastric ulcer & Suffered/Not suffered & 9 & - & - & 29 & 0.55 & $0.06-5.39$ \\
\hline
\end{tabular}

${ }^{*}$ Relative risks were calculated using the conditional logistic regression method (Breslow, 1978) with PHREG on SAS (ver. 6.04) based on the proportional hazard model by Cox (1972).

Variables were calculated as binomial variables in the univarite analysis

fish and smoked foods were almost same as unity, as shown in Table 5. However, in the differentiated type in older age groups, the relative risks elevated above 2 for pickled vegetables, salty foods, and dried fish and smoked foods, although these were not statistically significant.

In all subgroups, gastric ulcer history showed no striking relative risk. Other diseases in the past were not reported almost at all.

\section{Reproductive histories}

In the Table 6 and Table 7, means of the variables related to reproductive life histories were compared

Table 5. Relative risks for gastric cancer by histological subgroups among older females.

\begin{tabular}{|c|c|c|c|c|c|c|c|}
\hline \multirow[b]{2}{*}{ Factor } & \multirow[b]{2}{*}{ Definition } & \multicolumn{3}{|c|}{ Differentiated carcinoma } & \multicolumn{3}{|c|}{ Undifferentiated carcinoma } \\
\hline & & $\begin{array}{l}\text { No. of } \\
\text { Cases }\end{array}$ & $\begin{array}{l}\text { Relative } \\
\text { risk* }\end{array}$ & $95 \%$ C.I. & $\begin{array}{l}\text { No. of } \\
\text { Cases }\end{array}$ & $\begin{array}{l}\text { Relative } \\
\text { risk* }\end{array}$ & 95\% C.I. \\
\hline Smoking & Smoker or Ex-smoker/Non-smoker & 27 & 0.57 & $0.17-1.95$ & 46 & 1.50 & $0.42-5.32$ \\
\hline Drinking & Drinker or Ex-drinker/Non-drinker & 28 & 1.17 & $0.39-3.47$ & 44 & 2.50 & $0.97-6.44$ \\
\hline Rice & 4 bowls or more per day/Less than 4 & 27 & 1.33 & $0.30-5.96$ & 43 & 3.33 & $0.92-12.11$ \\
\hline Noodles & Several a week or more/Less than that & 27 & 2.50 & $0.49-12.89$ & 44 & 0.33 & $0.04-3.21$ \\
\hline $\begin{array}{l}\text { Consumption of the soup } \\
\text { of the noodles }\end{array}$ & Almost all/Less than that & 29 & 1.00 & $0.20-4.96$ & 40 & 4.00 & $0.85-18.84$ \\
\hline Bread & 5 times per week or more / Less than 5 & 8 & - & - & 10 & - & - \\
\hline Pickled vegetables & Once a day or more/Less than once & 29 & 3.33 & $0.92-12.11$ & 42 & 1.33 & $0.56-3.16$ \\
\hline Salty foods & Once a day or more/Less than once & 28 & 3.00 & $0.61-14.86$ & 42 & 0.71 & $0.23-2.25$ \\
\hline Miso soup & Once a day or more/Less than once & 29 & 2.00 & $0.59-6.79$ & 41 & 0.80 & $0.32-2.03$ \\
\hline Dried fish, smoked foods & Once a day or more/Less than once & 29 & 2.25 & $0.69-7.31$ & 43 & 1.13 & $0.43-2.92$ \\
\hline Broiled fish & Once a day or more/Less than once & 27 & 1.43 & $0.54-3.75$ & 44 & 1.00 & $0.4-2.52$ \\
\hline Meat products & Once a day or more/Less than once & 27 & 0.71 & $0.23-2.25$ & 40 & 0.44 & $0.14-1.44$ \\
\hline Vegetables & Once a day or more/Less than once & 27 & 0.56 & $0.19-1.66$ & 43 & 0.78 & $0.29-2.09$ \\
\hline Edible wild plant & Once a day or more/Less than once & 27 & 1.00 & $0.06-15.99$ & 42 & 0.50 & $0.05-5.51$ \\
\hline Fruits & Once a day or more/Less than once & 28 & 0.83 & $0.25-2.73$ & 44 & 0.90 & $0.37-2.22$ \\
\hline Milk & Once a day or more/Less than once & 29 & 1.25 & $0.34-4.66$ & 40 & 0.43 & $0.17-1.12$ \\
\hline Dairy products & Once a day or more/Less than once & 27 & 1.00 & $0.32-3.10$ & 40 & 0.80 & $0.32-2.03$ \\
\hline Coffee & Once a day or more/Less than once & 27 & 1.00 & $0.25-4.00$ & 44 & 0.80 & $0.22-2.98$ \\
\hline History of gastric ulcer & Suffered/Not suffered & 31 & - & - & 47 & 1.00 & $0.25-4.00$ \\
\hline
\end{tabular}

* Relative risks were calculated using the conditional logistic regression method (Breslow, 1978) with PHREG on SAS

(ver. 6.04) based on the proportional hazard model by Cox (1972).

Variables were calculated as binomial variables in the univarite analysis 
Table 6. Means and differences of the mean between cases and controls for the measurements concerned with reproductive history by histological group among young females.

\begin{tabular}{|c|c|c|c|c|c|c|c|c|c|c|}
\hline \multirow{3}{*}{ Variable } & \multicolumn{5}{|c|}{ Differentiated } & \multicolumn{5}{|c|}{ Undifferentiated } \\
\hline & \multicolumn{2}{|c|}{ Case } & \multicolumn{2}{|c|}{ Control } & \multirow{2}{*}{$\mathrm{p}^{*}$} & \multicolumn{2}{|c|}{ Case } & \multicolumn{2}{|c|}{ Control } & \multirow{2}{*}{$\mathrm{p}^{*}$} \\
\hline & $\mathrm{N}$ & Mean & $\mathrm{N}$ & Mean & & $\mathbf{N}$ & Mean & $\mathrm{N}$ & Mean & \\
\hline Age (at entry) & 9 & 35.22 & 16 & 35.50 & 0.384 & 29 & 35.76 & 50 & 35.92 & 0.364 \\
\hline Age at first marriage & 8 & 23.25 & 14 & 26.50 & 0.063 & 23 & 24.22 & 38 & 23.84 & 0.406 \\
\hline Number of pregnancy & 9 & 1.78 & 15 & 2.00 & 0.771 & 29 & 2.66 & 50 & 2.66 & 0.874 \\
\hline Number of delivery & 9 & 1.56 & 15 & 1.61 & 0.924 & 29 & 2.03 & 49 & 1.86 & 0.483 \\
\hline Age at first pregnancy & 7 & 25.71 & 10 & 26.00 & 0.856 & 24 & 25.25 & 40 & 24.65 & 0.343 \\
\hline Age at first birth & 6 & 25.00 & 8 & 25.50 & 0.702 & 24 & 25.33 & 39 & 24.62 & 0.230 \\
\hline Age at menarche & 9 & 13.56 & 14 & 13.11 & 0.452 & 29 & 13.34 & 50 & 12.80 & 0.036 \\
\hline Menstruation cycle (days) & 6 & 28.67 & 7 & 30.17 & 0.060 & 20 & 27.90 & 28 & 28.68 & 0.302 \\
\hline Duration of menstruation (days) & 8 & 5.25 & 14 & 5.19 & 0.944 & 25 & 5.84 & 41 & 5.83 & 0.724 \\
\hline Total pregnant period (weeks) ${ }^{* *}$ & 6 & 60.83 & 9 & 77.92 & 0.355 & 19 & 83.47 & 29 & 88.76 & 0.458 \\
\hline Mean pregnant period per pregnancy (weeks) ${ }^{* *}$ & 6 & 31.78 & 9 & 36.50 & 0.497 & 19 & 35.27 & 29 & 29.29 & 0.021 \\
\hline Total $\mathrm{CEC}^{* * *}(\mathrm{ng} \cdot \mathrm{w} / \mathrm{ml})$ & 8 & 506.95 & 11 & 550.93 & 0.757 & 24 & 659.91 & 37 & 572.88 & 0.250 \\
\hline $\begin{array}{l}\text { Total } \mathrm{CEC}^{* * *} \text { during all pregnant } \\
\text { period }(\mathrm{ng} \cdot \mathrm{w} / \mathrm{ml})^{* *}\end{array}$ & 6 & 385.08 & 9 & 537.84 & 0.285 & 19 & 557.49 & 29 & 562.18 & 0.943 \\
\hline $\begin{array}{l}\text { Mean } \mathrm{CEC}^{* * *} \text { during all pregnant } \\
\text { period }(\mathrm{ng} / \mathrm{ml})^{* *}\end{array}$ & 6 & 5.42 & 8 & 6.42 & 0.488 & 19 & 6.64 & 28 & 6.00 & 0.000 \\
\hline
\end{tabular}

${ }^{*}$ Paired T-test for difference of the mean between cases and controls.

** Only females with pregnancy were analyzed.

***CEC : Cumulative estradiol concentration (roughly estimated indicator for estradiol exposure)

Estradiol concentration were cumulated from the age at menarche to the age at diagnosis for total CEC, only during pregnancy for total CEC during all pregnant period, and total CEC during all pregnant period was divided by total weeks of pregnancy for mean CEC during all pregnant period.

between cases and controls by age and histological types. In undifferentiated type of young group, mean pregnant period per pregnancy and mean CEC (Cumulative estradiol concentration) during all pregnant period were significantly higher in cases than in controls among female with pregnancy. In the same group, age at menarche was higher in the cases with weak statistical significance. In differentiated type among young group, age at the first marriage and menstruation cycle tended to be lower in cases. In the older group, there were no variables with significant difference between cases and controls, as shown in Table 7.

Relative risks of reproductive histories for gastric cancer were shown in Table 8. In the undifferentiated type of the young group, mean CEC during all pregnant period had a statistically significant rise in the risk, 7.7 fold for each unit of the estimated concentration. After adjusted by drinking habit and amount of rice consumption per day, adjusted relative risk for mean CEC during all pregnant period was 12.4 with 95\% C.I. 1.45-105.2. Mean of pregnant period also showed relative risk of 3.1. In other subgroups, these elevated risks could not be seen.

The total CEC and the total CEC during all pregnant period did not suggest any risk in all subgroups. Other reproductive histories did not show any obvious risk in all subgroups, neither. Therefore, in the subgroups except young undifferentiated group, there seemed to be no obvious risk change in reproductive histories.

\section{DISCUSSION}

In the present study, information bias should not be serious, because reproductive factors were not to be recognized as risk factors for gastric cancer in general population, and because patients with gastric cancer did not know the histological type of their gastric cancer. Selection criteria for cases and controls seemed not to be related to dietary factors and reproductive factors in the study. Therefore, selection bias might not be important for this study.

Concerning the differences between two histological types, Haenszel et al. analyzed dietary factors in the Japanese in Hawaii dividing cases into two subcategories, following Lauren's criteria, intestinal and diffuse types ${ }^{11)}$. They asserted that salty food consumption showed a higher risk in the intestinal type than in the diffuse type. But in a consequent survey in Japan, they could not find any remarkable differences between the two histological types $^{12)}$. Buiatti also suggested that the intestinal and diffuse type of gastric cancer had etiologic factors in common $^{13)}$.

From the pathological point of view, Lauren ${ }^{14)}$, Na- 
kamura et al. ${ }^{15)}$ and Sugano et al. ${ }^{16)}$ compared two histological subgroups of gastric cancer and suggested that two histological type of gastric cancer had different etiology, and Nakamura and Sugano asserted that "undifferentiated type" must be the proper form of stomach cancer ${ }^{15,16)}$.

No report was appeared on difference of the risk of daily habits between age classes. Kikuchi analyzed only cases of ages of 40 and younger, and concluded that smoking, drinking and obesity were not related with gastric cancer risk, and that gastric cancers occurred in young adults were affected little from environmental factors ${ }^{17}$.

In our study, drinking habit and amount of rice per day decreased the risk, 0.23 and 0.20 , in undifferentiated type of the young group.

Rice was reported as a risk factor ${ }^{11,18,19,20)}$. Haenszel found that rice showed higher risk in intestinal type than in diffuse type ${ }^{11)}$. But in some papers, rice had little effect on the gastric cancer ${ }^{21,22)}$, even when it had been analyzed separately by histological type ${ }^{23)}$. Drinking habit had been considered as neither risk factor nor protective factor in many papers ${ }^{19,22)}$, even when it was analyzed individually by histological type ${ }^{23)}$. Protective effects of drinking habit and rice consumption among undifferentiated type of the young group in this study did not coincide with former knowledge from studies without analyses by age.

Pickled vegetable, salty and smoked foods, and broiled fish seemed to increase the gastric cancer risk in the differentiated histological type group of both age group, though they were not statistically significant, and fruits seemed to reduce the risk in the same groups, even though it was not statistically significant. These risk factors and protective factors which showed weak effect in this study were all pointed out in former studies as major factors for gastric cancer in general, without consideration of age ${ }^{11-13,18-23)}$. But, in this study, these factors seemed to be appeared more in differentiated type group than in undifferentiated group, and to effect more in the older females than in the young.

From different distribution of the risk between two histological types presented above, it was suggested that there would be etiologic differences between two histological types when it was analyzed separately by age. Further study should be required to answer this question.

Concerning the reproductive life histories, age at the menarche, mean pregnant period per pregnancy and mean CEC during all pregnant period were significantly higher in cases than in controls only among undifferentiated type of young group. Increased relative risks was also obtained for mean pregnant period per pregnancy and

Table 7. Means and differences of the mean between cases and controls for the measurements concerned with reproductive history by histological group among older females.

\begin{tabular}{|c|c|c|c|c|c|c|c|c|c|c|}
\hline \multirow{3}{*}{ Variable } & \multicolumn{5}{|c|}{ Differentiated } & \multicolumn{5}{|c|}{ Undifferentiated } \\
\hline & \multicolumn{2}{|c|}{ Case } & \multicolumn{2}{|c|}{ Control } & \multirow{2}{*}{$\mathrm{p}^{*}$} & \multicolumn{2}{|c|}{ Case } & \multicolumn{2}{|c|}{ Control } & \multirow{2}{*}{$\mathrm{p}^{*}$} \\
\hline & $\mathrm{N}$ & Mean & $\mathrm{N}$ & Mean & & $\mathrm{N}$ & Mean & $\mathrm{N}$ & Mean & \\
\hline Age (at entry) & 31 & 54.52 & 31 & 54.58 & 0.730 & 47 & 54.72 & 47 & 54.66 & 0.722 \\
\hline Age at first marriage & 27 & 23.93 & 27 & 22.81 & 0.329 & 36 & 23.83 & 36 & 23.61 & 0.746 \\
\hline Number of pregnancy & 28 & 3.68 & 28 & 3.46 & 0.554 & 45 & 3.22 & 45 & 3.62 & 0.273 \\
\hline Number of delivery & 27 & 2.30 & 27 & 2.33 & 0.885 & 43 & 2.16 & 43 & 2.12 & 0.851 \\
\hline Age at first pregnancy & 25 & 24.36 & 25 & 23.84 & 0.617 & 36 & 25.31 & 36 & 24.69 & 0.521 \\
\hline Age at first birth & 24 & 24.75 & 24 & 24.21 & 0.604 & 30 & 24.83 & 30 & 24.27 & 0.539 \\
\hline Age at menarche & 28 & 14.96 & 28 & 15.18 & 0.631 & 45 & 14.82 & 45 & 14.47 & 0.376 \\
\hline Menstruation cycle (days) & 14 & 28.50 & 14 & 28.86 & 0.583 & 24 & 28.25 & 24 & 28.00 & 0.625 \\
\hline Duration of menstruation (days) & 24 & 5.42 & 24 & 5.08 & 0.466 & 36 & 5.25 & 36 & 5.61 & 0.338 \\
\hline Total pregnant period (weeks) ${ }^{* *}$ & 14 & 105.07 & 14 & 94.29 & 0.262 & 14 & 102.71 & 14 & 105.93 & 0.850 \\
\hline Mean pregnant period per pregnancy (weeks) ${ }^{* *}$ & 14 & 30.15 & 14 & 33.49 & 0.157 & 14 & 26.01 & 14 & 26.29 & 0.943 \\
\hline Total $\mathrm{CEC}^{* * *}(\mathrm{ng} \cdot \mathrm{w} / \mathrm{ml})$ & 15 & 808.17 & 15 & 765.18 & 0.632 & 15 & 781.15 & 15 & 821.41 & 0.718 \\
\hline $\begin{array}{l}\text { Total } \mathrm{CEC}^{* * *} \text { during all pregnant } \\
\text { period }(\mathrm{ng} \cdot \mathrm{w} / \mathrm{ml})^{* * *}\end{array}$ & 14 & 615.80 & 14 & 594.42 & 0.778 & 14 & 617.61 & 14 & 622.84 & 0.963 \\
\hline $\begin{array}{l}\text { Mean } \mathrm{CEC}^{* * *} \text { during all pregnant } \\
\text { period }(\mathrm{ng} / \mathrm{ml})^{* *}\end{array}$ & 14 & 5.83 & 14 & 6.22 & 0.387 & 14 & 5.24 & 14 & 5.46 & 0.790 \\
\hline
\end{tabular}

${ }^{*}$ Paired T-test for difference of the mean between cases and controls.

** Only females with pregnancy were analyzed.

*** CEC : Cumulative estradiol concentration (roughly estimated indicator for estradiol exposure) Estradiol concentration were cumulated from the age at menarche to the age at diagnosis for total CEC, only during pregnancy for total CEC during all pregnant period, and total CEC during all pregnant period was divided by total weeks of pregnancy for mean CEC during all pregnant period. 
mean CEC during all pregnant period. But, total CEC and total CEC during all pregnancy did not show any increased relative risk, not only in undifferentiated young group but also in other subgroups.

The result that the total CEC and the total CEC during all pregnancy did not show increased risk suggests that the amount of estradiol exposed during her pregnancy or life time did not affect incidence of stomach cancer.

Mean CEC during all pregnant period and mean pregnant period per pregnancy will have maximum value when all pregnancies of one subject terminated at full term in spite of when number of pregnancy experienced was large. These measures may represent the weight of the pregnancies in later stage among all pregnant period rather than the amount of estradiol exposed through her pregnancy.

In this study, proportion of gallstone disease among controls were very high, $33.3 \%$ for the young and $53.8 \%$ for the older. Pregnancy and extraneous female sex hormone were thought to be risk factors for gallstone disease.

Table 8. Relative risks of reproductive histories for gastric cancer by histological subgroups among females.

\begin{tabular}{|c|c|c|c|c|c|c|c|}
\hline \multirow[b]{2}{*}{ Factor } & \multirow[b]{2}{*}{ Definition } & \multicolumn{3}{|c|}{ Differentiated carcinoma } & \multicolumn{3}{|c|}{ Undifferentiated carcinoma } \\
\hline & & $\begin{array}{l}\text { No. of } \\
\text { Cases }\end{array}$ & $\begin{array}{l}\text { Relative } \\
\text { risk }\end{array}$ & 95\% C.I. & $\begin{array}{l}\text { No. of } \\
\text { Cases }\end{array}$ & $\begin{array}{l}\text { Relative } \\
\text { risk }\end{array}$ & $95 \%$ C.J. \\
\hline \multicolumn{8}{|l|}{ Young females } \\
\hline Age at menarche & 14 y.o. or more/Less than 14 & 9 & 1.66 & $0.36-7.72$ & 29 & 1.65 & $0.62-4.39$ \\
\hline Age at first marriage & 24 y.o. or more/Less than 24 & 8 & 0.17 & $0.02-1.61$ & 23 & 2.03 & $0.60-6.85$ \\
\hline Number of pregnancy & 3 or more/Less than 3 & 9 & 0.86 & $0.13-5.53$ & 29 & 0.74 & $0.31-1.79$ \\
\hline Number of delivery & 3 or more/Less than 3 & 9 & 0.78 & $0.07-8.88$ & 29 & 0.92 & $0.34-2.48$ \\
\hline Age at first pregnancy & 24 y.o. or more/Less than 24 & 7 & 1.62 & $0.14-18.31$ & 24 & 2.60 & $0.71-9.55$ \\
\hline Age at first birth & 24 y.o. or more/Less than 24 & 6 & - & - & 24 & 2.73 & $0.57-13.06$ \\
\hline $\begin{array}{l}\text { Mean pregnant period } \\
\text { per pregnancy** }\end{array}$ & for each 10 weeks & 6 & 0.72 & $0.25-2.03$ & 19 & 3.11 & $1.01-9.55$ \\
\hline Total CEC $* * *$ & for each $100 \mathrm{ng}$ weeks $/ \mathrm{ml}$ & 8 & 0.95 & $0.72-1.25$ & 24 & 1.09 & $0.91-1.30$ \\
\hline $\begin{array}{l}\text { Total } \mathrm{CEC}^{* * *} \text { during all } \\
\text { pregnant period** }\end{array}$ & for each $100 \mathrm{ng}$ weeks $/ \mathrm{ml}$ & 8 & 0.99 & $0.77-1.28$ & 24 & 1.09 & $0.91-1.31$ \\
\hline $\begin{array}{l}\text { Mean } \mathrm{CEC}^{* * *} \text { during all } \\
\text { pregnant period }^{* *}\end{array}$ & for each $1 \mathrm{ng} / \mathrm{ml}$ & 6 & 0.88 & $0.56-1.38$ & 19 & 7.68 & $1.41-41.75$ \\
\hline \multicolumn{8}{|l|}{ Older females } \\
\hline Age at menarche & 14 y.o. or more/Less than 14 & 28 & 0.71 & $0.06-1.38$ & 45 & 1.50 & $0.61-3.67$ \\
\hline Age at first marriage & 24 y.o. or more/Less than 24 & 27 & 1.00 & $0.35-2.85$ & 36 & 1.10 & $0.47-2.59$ \\
\hline Number of pregnancy & 3 or more/Less than 3 & 28 & 1.25 & $0.34-4.66$ & 45 & 0.70 & $0.27-1.84$ \\
\hline Number of delivery & 3 or more/Less than 3 & 27 & 1.33 & $0.46-3.84$ & 43 & 0.75 & $0.32-1.78$ \\
\hline Age at first pregnancy & 24 y.o. or more/Less than 24 & 25 & 1.00 & $0.32-3.10$ & 36 & 1.13 & $0.43-2.92$ \\
\hline Age at first birth & 24 y.o. or more/Less than 24 & 24 & 2.50 & $0.49-12.89$ & 30 & 1.20 & $0.37-3.93$ \\
\hline $\begin{array}{l}\text { Mean pregnant period } \\
\text { per pregnancy** }\end{array}$ & for each 10 weeks & 14 & 0.35 & $0.07-1.69$ & 14 & 0.97 & $0.46-2.07$ \\
\hline Total CEC $* * *$ & for each $100 \mathrm{ng}$ weeks $/ \mathrm{ml}$ & 15 & 1.07 & $0.80-1.44$ & 15 & 0.95 & $0.74-1.23$ \\
\hline $\begin{array}{l}\text { Total CEC } \\
\text { pregnant period }{ }^{* *}\end{array}$ & for each $100 \mathrm{ng}$ weeks $/ \mathrm{ml}$ & 14 & 1.06 & $0.72-1.57$ & 14 & 0.99 & $0.77-1.29$ \\
\hline $\begin{array}{l}\text { Mean } C E C^{* * *} \text { during all } \\
\text { pregnant period** }\end{array}$ & for each $1 \mathrm{ng} / \mathrm{ml}$ & 14 & 0.72 & $0.35-1.51$ & 14 & 0.95 & $0.67-1.36$ \\
\hline
\end{tabular}

*Relative risks were calculated using the conditional logistic regression method (Breslow, 1978) with PHREG on SAS (ver. 6.04) based on the proportional hazard model by Cox (1972).

**Only females with pregnancy were analyzed.

${ }^{* * *}$ CEC : Cumulative estradiol concentration (roughly estimated indicator for estradiol exposure)

Estradiol concentration were cumulated from the age at menarche to the age at diagnosis for total CEC, only during pregnancy for total CEC during all pregnant period, and total CEC during all pregnant period was divided by total weeks of pregnancy for mean CEC during all pregnant period.

Variables were calculated with binomial value other than mean pregnant period per pregnancy, total CEC. total CEC during all pregnant period and mean CEC during all pregnant period. These four variables used with their continuous values, for each 10 (weeks) for mean pregnant period per pregnancy, for each 100 (ng weeks $/ \mathrm{ml}$ ) rise for total CEC and total CEC during all pregnant period and for each $1(\mathrm{ng} / \mathrm{ml})$ risw for mean $\mathrm{CEC}$ during all pregnant period. 
Estimated total CEC during all pregnant period and mean CEC during all pregnant period were higher in the controls with gallstone disease than those without it among young females. But among older females, these indices were almost equal in both groups. This suggest that the risk differences of total CEC during all pregnant period and mean CEC during all pregnant period would be decreased between cases and controls. Braverman proposed the hypothesis that abnormal gallbladder function in the latter two third of pregnancy contribute to the formation of cholesterol gallstones ${ }^{24}$. It is similar to become latter two third of pregnancy with that mean pregnant period per pregnancy were longer in the cases in young undifferentiated group, and this suggest that risk difference of the mean pregnant period per pregnancy between cases and controls would be decreased in this study. As mentioned above, high proportion of gallstone disease among controls in this study might arise underestimated risk of pregnancy and related factors.

Some reports concerned reproductive life history on gastric cancer ${ }^{3,6,7,13,25)}$. Yoshimura ${ }^{3)}$ and Tsukuma ${ }^{25}$ investigated young females. Others treated cases mainly aged over 50. Tsukuma reported that among females of 30 to 34 years of age, relative risk was 0.36 when they had ever been pregnant. Yoshimura didn't found any obviously elevated risk for number of pregnancy or delivery. Among subjects most of whom were aged 50 years or more, Vecchia showed increasing trend of relative risk with number of birth ${ }^{7}$. In that study, they presented discordant effect of oral contraceptive and estrogen replacement, the former showed weak risk and the latter showed weak protective effect ${ }^{7}$. Number of pregnancy and number of delivery (or birth) were assessed in these studies. But, none of these studies concerned about length of pregnant period and evaluated the percentage of delivery among all pregnancies, and none of them analyzed separately by histological type and age.

Concerning the direct effect of estrogens on gastric cancer incidence, Furukawa and his colleagues suggested that estrogens suppressed the induction of gastric carcinoma (mainly differentiated) in male rat, induced by MNNG (N-methyl-N'-nitro-N-nitrosoguanidine) ${ }^{4}$. It was also reported that the number of poorly differentiated stomach region increased in rat which were injected with estrogen ${ }^{4)}$. Then, they observed that the incidence of gastric cancer was higher in rats with delivery than in those without pregnancy or in those were resected pregnant uterus and ovaries early in the pregnancy ${ }^{5}$. From these result, they suggested that the sudden decrease of estrogen concentration at delivery might be a factor for increased risk of gastric cancer.

Tsukuma et al. reported that among human females aged 16 to 29 , odds ratio had been 5.75 when they had diagnosed gastric cancer within 24 month after the delivery compared with those who had been diagnosed at 61 month or more after the delivery and suggested that pregnancy affected gastric cancer incidence, but they presented no hypothesis upon the mechanism and didn't analyzed separately by histological type ${ }^{25}$.

In human females, no report was appeared on gastric cancer, considering hormonal factor itself or length of pregnancies by histological type and by age group. The result of this study suggested that estradiol would not affect on the gastric cancer with hormonal activity of itself, but something in the pregnancy courses would act on initiation or promotion of gastric cancer at least in female with pregnancy in young undifferentiated type. Furukawa's suggestion of the risk increase by the sudden decrease of estrogen concentration at delivery might be one hypothesis for effect of pregnancy on gastric cancer. But, there were no direct evidence in this study that suggested the relation between sudden decrease of estrogen concentration and gastric cancer incidence.

Our study suggested that risk factors for gastric cancer are different between histological types and age classes and that gastric cancers of females may be partly affected by pregnancy and some kind of physiological condition related to pregnancy especially in the undifferentiated histological type of young female with pregnancy. Other epidemiological and experimental studies are expected to clarify the effect of the factors related to pregnancy on gastric cancer risk.

\section{ACKNOWLEDGMENTS}

We are deeply indebted for the cooperation given us by doctors in the hospitals where subjects were surveyed, with address at the time survey running and the alphabetic order of the hospital name.

Dr. K. Tanaka (The Center for Adult Disease, Fukuoka Medical Association), Dr. H. Shimura and Dr. H. Umeno (First Department of Surgery, Fukuoka University Hospital), Dr. S. Inutsuka, Dr. R. Kumashiro and Dr. H. Naito (Second Department of Surgery, Fukuoka University Hospital), Dr. N. Kondo and Dr. H. Tateishi (Department of Surgery, Izuka Hospital), Dr. Y. Nakamura, Dr. Y. Hamanaka, Dr. S Koga and Dr. T. Iwashita (Department of Surgery, Kokura Hospital), Dr. K. Kodama (Department of Surgery, Kyushu Kousei-nenkin Hospital), Dr. F. Nakayama, Dr. J Yanagisawa, Dr. H. Ichimiya and Dr. R. Mibu (Department of Surgery I, Kyushu University Hospital), Dr. K. Sugimachi, Dr. K. Okamura and Dr. D. Korenaga (Department of Surgery II, Kyushu University Hospital), Dr. M. Saku (Department of General Surgery, National Fukuoka Central Hospital), Dr. M. Furusawa (Department of Gastroenterological Surgery, National Kyushu Cancer Center), Dr. M. Moriyama (Department of Surgery, Saiseikai Yahata Hospital), Dr. K. Ohsato and Dr. Y. Kuroda (Department of General and Abdominal Surgery, University of Occupational and Environmental Health Hospital), Dr. H. Kishikawa (Department of Surgery, Wakamatsu Hospital). Without their cooperation this study would not have been possible. We also wish to thank Ms. N. Akazome and Ms. K. Yamaguchi for their assistance. 


\section{REFERENCES}

1. Griffith GW. The sex ratio in gastric cancer and hypothetical considerations relative to etiology. Br J Cancer, 1968; 22: 163-172.

2. Sawada T, Akashi A. Gastric cancer in youth. Gan no Rinsho, 1956 ; 2 : 294-297 (in Japanese)

3. Yoshimura T, Kato H. Gastric cancer in youth and reproductive life history. Jpn J Hyg, 1985; 40:110 (in Japanese).

4. Furukawa $\mathrm{H}$, Iwnaga $\mathrm{T}$, Terasawa $\mathrm{T}$, Ishikawa $\mathrm{O}$, Taniguchi H. Effect of estrogen on gastric cancer. Nippon Shokakibyo Gakkai Zasshi, 1979; 76 : 2376-2381 (in Japanese).

5. Furukawa $H$, Iwanaga $T$, Tateishi $R$, Taniguchi $H$. Experimental study of carcinogenesis of the rat stomach during pregnancy, delivery and lactation. Nippon Shokaki Geka Gakkai Zasshi, 1987; $20: 856-859$ (in Japanese).

6. Palli D, Cipriani F, Decarli A, et al. Reproductive history and gastric cancer among post-menopausal women. Int $\mathrm{J}$ Cancer, $1994 ; 56 ; 812-815$.

7. Vecchia C, D'Avanzo B, Franceshi S, et al, Menstrual and reproductive factors and gastric-cancer risk in women. Int $\mathrm{J}$ Cancer, $1994 ; 59 ; 61-764$.

8. Hanai A, Matsuo S, Kawai M, Fujimoto I, Taniguchi H. Trend of histological distribution of stomach cancer in Osaka. Gan no Rinsho, 1981; 27 : 1813-1819 (in Japanese).

9. De Hertogh R, Thomas K, Bietlot Y, Vanderheyden I, Ferin J. Plasma levels of unconjugated estrone, estradiol and estriol and of HCS throughout pregnancy in normal women. J Clin Endocrinol Metab, 1975; $40: 93-101$.

10. SAS Technical Report P-229, SAS/STAT Software: Changes and Enhancements, Release 6.07. Chapter 19. The PHREG Procedure. SAS Institute Inc., Cary, NC, USA. 1992.

11. Haenszel W, Kurihara M, Locke FB, Shimizu K, Segi M. Stomach cancer among Japanese in Hawaii. J Natl Cancer Inst., $1972 ; 49$ : 969-988.

12. Haenszel W, Kurihara M, Locke FB, Shimizu K, Segi M. Stomach cancer in Japan. J Natl Cancer Inst. 1976; 56 :
265-274.

13. Buiatti E, Palli D, Bianchi S, et al. A case-control study of gastric cancer and diet in Italy. III. Risk patterns by histologic type. Int J Cancer, 1991 ; 48 : 369-374.

14. Lauren Pekka. The two histological main types of gastric carcinoma : Diffuse and so-called intestinal-type carcinoma. Acta Path et Microbiol Scandinav, 1965; 64: 31-49.

15. Nakamura K, Sugano H, Takagi K, Kumakura K. Histogenesis of carcinoma of stomach with special reference to 50 primary microcarcinomas : Light- and Electron-microscopie, and statistical studies. Gan no Rinsho, 1969; 7: 627-647 (in Japanese).

16. Sugano $H$. Natural history of human cancer. $\operatorname{Tr} \mathrm{Soc}$ Pathol Jpn, 1980; 69: 27-57 (in Japanese).

17. Kikuchi S, Inaba $\mathrm{Y}$, Wada $\mathrm{O}$, et al. How do we prevent the death of stomach cancer in young men? Gan no Rinsho, $1991 ; 37$ 235-238 (in Japanese).

18. Kurihara $\mathrm{H}$. Clinical epidemiology of gastric cancer. Kanahara Shuppan, 1980.

19. Tajima K, Tominaga S. Dietary habits and gastro-intestinal cancers: A comparative case-control study of stomach and large intestinal cancers in Nagoya, Japan. Jpn J Cancer Res, $1985 ; 76: 705-716$

20. Kato I, Tominaga S. Gastric cancer and diet and meal. Koshu Eisei, 1987; 51 : 197-202 (in Japanese).

21. Kono S, Ikeda M, Tokudome S, Kuratsune M. A CaseControl Study of Gastric Cancer and Diet in Northern Kyushu, Japan. Jpn J Cancer Res, 1988; 79 : 1067-1074.

22. Kato I, Tominaga S, Ito I, et al. A prospective study of atrophic gastritis and stomach cancer risk. Jpn J Cancer Res, 1992; 83 : 1137-1142.

23. Kato I, Tominaga $\mathrm{S}$, Ito $\mathrm{Y}$, et al. A comparative casecontrol analysis of stomach cancer and atrophic gastritis. Cancer Res, 1990; 50 : 6559-6564.

24. Braverman DZ, Johnson ML, and Kern F, Jr. Effects of pregnancy and contraceptive steroids on gallbladder function. N Eng J Med, 1980; 302: 362-364.

25. Tsukuma H, Fujimoto I, Furukawa $\mathrm{H}$, et al. A case-control study of stomach cancer in young females, with special reference to the effects of pregnancy and delivery. Gan no Rinsho, $1989 ; 35: 35-40$ (in Japanese). 